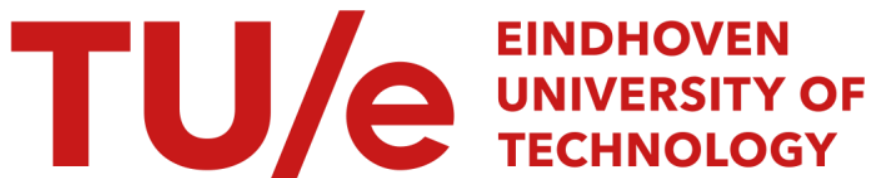

\section{The dynamic behaviour of rail fasteners at high frequencies}

Citation for published version (APA):

Thompson, D. J., \& Verheij, J. W. (1997). The dynamic behaviour of rail fasteners at high frequencies. Applied Acoustics, 52(1), 1-17. https://doi.org/10.1016/S0003-682X(97)00016-9

DOI:

10.1016/S0003-682X(97)00016-9

Document status and date:

Published: 01/01/1997

\section{Document Version:}

Publisher's PDF, also known as Version of Record (includes final page, issue and volume numbers)

\section{Please check the document version of this publication:}

- A submitted manuscript is the version of the article upon submission and before peer-review. There can be important differences between the submitted version and the official published version of record. People interested in the research are advised to contact the author for the final version of the publication, or visit the $\mathrm{DOI}$ to the publisher's website.

- The final author version and the galley proof are versions of the publication after peer review.

- The final published version features the final layout of the paper including the volume, issue and page numbers.

Link to publication

\section{General rights}

Copyright and moral rights for the publications made accessible in the public portal are retained by the authors and/or other copyright owners and it is a condition of accessing publications that users recognise and abide by the legal requirements associated with these rights.

- Users may download and print one copy of any publication from the public portal for the purpose of private study or research.

- You may not further distribute the material or use it for any profit-making activity or commercial gain

- You may freely distribute the URL identifying the publication in the public portal.

If the publication is distributed under the terms of Article 25fa of the Dutch Copyright Act, indicated by the "Taverne" license above, please follow below link for the End User Agreement:

www.tue.nl/taverne

Take down policy

If you believe that this document breaches copyright please contact us at:

openaccess@tue.nl

providing details and we will investigate your claim. 


\title{
The Dynamic Behaviour of Rail Fasteners at High Frequencies
}

\author{
D. J. Thompson ${ }^{a}$ and J. W. Verheij ${ }^{b}$ \\ ${ }^{a}$ Institute of Sound and Vibration Research, University of Southampton, Highfield, \\ Southampton, UK, SO17 IBJ \\ ${ }^{b}$ TNO Institute of Applied Physics, PO Box 155, 2600 AD Delft, \\ The Netherlands \\ (Received 26 January 1996; revised version received 17 January 1997; \\ accepted 6 March 1997)
}

\begin{abstract}
$A B S T R A C T$
The stiffness and damping of rail fasteners, and in particular the elastomeric pads inserted between the rail and sleeper, are important parameters determining the dynamic behaviour of railway track. For noise predictions, the frequency range from about $100 \mathrm{~Hz}$ up to $5000 \mathrm{~Hz}$ is important. Laboratory measurements are described in which the vertical and lateral dynamic stiffnesses of rail fastener systems have been measured under preload in the range 100-1000 Hz. Extension of the method to higher frequencies is also possible but would require a modified test arrangement. Field measurements are also described, which allow the stiffness and damping to be derived indirectly. Comparisons are made between the two sets of data.

(C) 1997 Elsevier Science Ltd.
\end{abstract}

Keywords: Dynamic stiffness, measurement method, railway track.

\section{INTRODUCTION}

The dynamic hehaviour of track plays an important role in the generation of wheel-rail rolling noise. Vibrations, generated at the contact zone, are transmitted through the track and wheel structures, and these vibrations are then responsible for radiating airborne noise. The track dynamic behaviour influences this process through the wheel-rail interaction and also by affecting 
the transmission of vibrations both along the track and from the rail to the sleepers. The high frequency dynamic behaviour at the contact point is also important for the deterioration of the running surface (e.g. corrugation), which in turn influences the noise generation.

Theoretical models have been developed which enable predictions to be made of wheel-rail rolling noise for a given combination of wheel and rail designs, for example the models incorporated into the computer package, TWINS. ${ }^{1-3}$ Such models require data on the high-frequency dynamic stiffness and damping of the ballast and the rail fasteners, in particular the elastomeric pads inserted between the rail and sleeper.

Elastomeric materials, such as those used for the rail pads, can have a much higher stiffness at high frequencies than statically, or even than in a traditional 'dynamic' test at a few Hertz. A laboratory measurement method is described here which allows the dynamic stiffness of rail fasteners to be determined for frequencies $100-1000 \mathrm{~Hz}$. Extension of the method to higher frequencies is also possible. Comparisons are also made between results from this method and data derived indirectly from field measurements.

The stiffness of elastomeric materials is generally dependent on frequency, amplitude (strain), static preload and temperature. The method used aims to plot the dependence on frequency for appropriate preloads, whilst making use of the fact that for small strains the behaviour is independent of amplitude. For example, in Ref 4 results are shown for butyl rubber with various proportions of carbon for which the amplitude of the shear modulus remains constant for peak-peak strain amplitudes up to about $0.3 \%$, whilst the phase of the shear modulus is constant up to about $0.1 \%$ strain amplitude. Hinsch ${ }^{5}$ shows low amplitude moduli valid up to typically $0.2 \%$, in some cases $0.4 \%$. Such small strains are typical for the high frequency behaviour of rail fasteners, as will be shown later in the paper. On the other hand, the quasi-static loading of a passing wheel introduces preloading of the system, which is also taken into account in the method. The time-variance of this loading is ignored in the current work, but could also be introduced. Dependence on temperature has not yet been studied, all laboratory measurements reported here being carried out at room temperature $\left(\right.$ c. $\left.20^{\circ} \mathrm{C}\right)$.

A distinction is made in this paper between unloaded fastener stiffnesses, which will be important in determining the propagation of vibrations along the rail, and the stiffnesses under loading from a wheel, which will be important for the track response at the wheel-rail contact and the transfer of vibrations to the sleeper. However, it should be pointed out that the track models currently used in TWINS ${ }^{1-3}$ do not take account of any difference between these two stiffness values. 


\section{METHOD}

A measurement method has been chosen in which the rail fasteners can be measured in their entirety, so that not only the material properties but also the geometrical factors can be measured. The effects of the rest of the fastening system (spring clips) can thereby also be taken into account.

A so-called indirect method has been developed, ${ }^{6,7}$ in which the resilient element is placed between two massive blocks (Fig. 1), this whole arrangement being resiliently mounted with respect to the test rig. A static preload can be introduced hydraulically in the vertical direction (also a negative preload is possible to partially compensate for the upper block). The upper block is excited electro-dynamically, and the response of both blocks is measured using accelerometers. Pairs of accelerometers, accurately positioned with respect to the centreline, are used to allow pure translations and rotations to be separated. Excitation and response measurements are

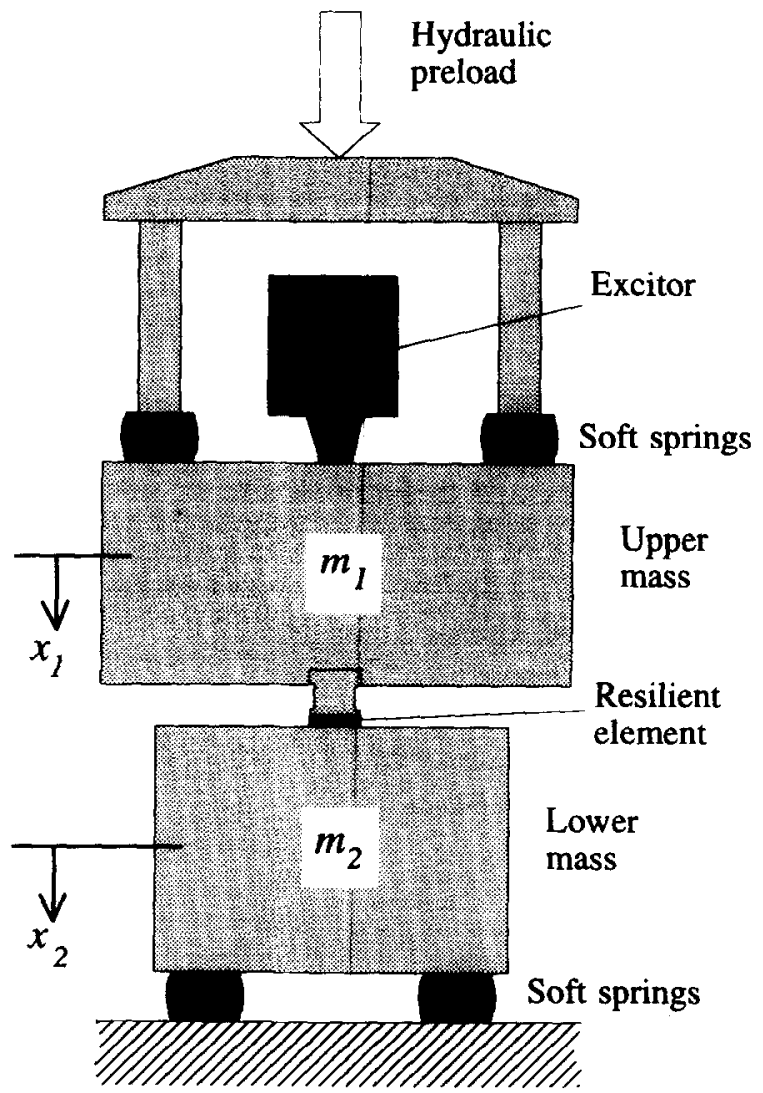

Fig. 1. Test rig for measuring high-frequency dynamic stiffness of resilient elements under preload. 
possible in all six degrees of freedom allowing the whole transfer function matrix to be determined (i.e. maximally 36 elements, although often many are zero or equal to another due to symmetry considerations). In the experiments described, however, only vertical and lateral translational transfer functions have been considered.

The measurement method is designed to measure the transfer stiffness of resilient elements, that is the blocked force transmitted per unit displacement input at the free side of the element. The lower side of the resilient element experiences a high impedance, and is effectively blocked, so the deflection in the element is approximately equal to the displacement of the upper side. The force transmitted through the element is measured indirectly from the small acceleration of the lower block, multiplied by its mass. The (complex) stiffness $K$, including damping loss factor $\eta$, is thus derived from the accelerations of the two blocks:

$$
K \approx-m_{2} \omega^{2} \frac{\ddot{x}_{2}}{\ddot{x}_{1}} ; \eta=\tan (\angle K)
$$

Although called a stiffness, this quantity in fact implicitly includes effects of internal mass, which will result in internal resonances at very high frequencies. Where internal mass is insignificant, the transfer stiffness will equal the input stiffness, that is the reaction force on the upper block will equal the force transmitted to the lower block. The mass of the rail or baseplate is included into the masses $m_{1}$ and $m_{2}$.

The frequency range in which measurements can be made depends on the mass of the lower block and the stiffness of the resilient element to be measured. Valid measurements are possible from about 2-3 times the eigenfrequency corresponding to these two elements $\left(\omega=\left(K m_{2}{ }^{-1}\right)^{1 / 2}\right)$. At high frequencies, the measurement method is limited by instrumentation noise in the vibration signal from the lower block (which becomes much smaller than that of the top block) or interference, for example, by airborne sound transfer between the two blocks. The vibrational modes of the lower block must also be avoided, since it is assumed that its effective mass $m_{2}$ is independent of frequency. For the tests described, a lower mass of $1600 \mathrm{~kg}$ has been used, which gives reasonable results up to about $1 \mathrm{kHz}$. The upper block was excited by a swept-sine signal which yielded an r.m.s. acceleration amplitude of this block of approximately $0.2-0.3 \mathrm{~ms}^{-2}$. A preload of $40 \mathrm{kN}$ has mostly been used, which corresponds approximately to the maximum load which would occur during the passage of a passenger train.

The same test rig has been used in some cases to measure static stiffnesses by gradually applying and then removing the hydraulic preload whilst measuring the relative displacement of the two blocks using a simple dial gauge. 


\section{RESULTS}

\section{Fasteners for use in plain track}

The following five systems have been measured, all except one intended for use in ballasted track (Fig. 2).

(1) Nabla fasteners with $4.5 \mathrm{~mm}$ ribbed rubber pad, MRE89;

(2) Vossloh fasteners with thin rubber pad, Zw687a;

(3) 'Rheda modifiziert' two-stage soft fastener (6 mm pad (Zw692-6), $16 \mathrm{~mm}$ steel plate and $10 \mathrm{~mm}$ soft pad, with Vossloh fasteners) used in ballastless track, with sleepers cast into concrete slab;

(4) FC9 $4.5 \mathrm{~mm}$ cork-rubber pads and DE spring clips;

(5) EVA $4.5 \mathrm{~mm}$ rubber pad, on a wooden sleeper (DE spring clips or $\mathrm{K}$-fasteners).

(a)

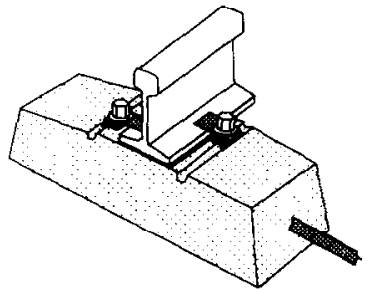

(c)

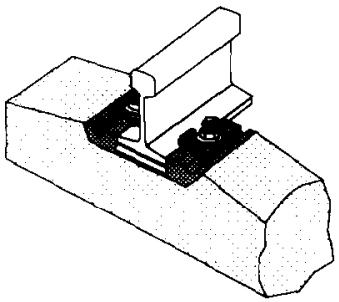

(b)

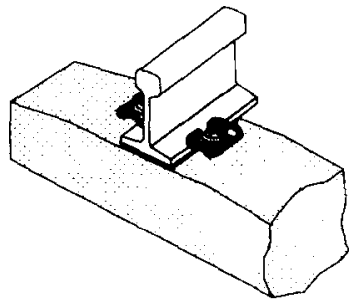

(d)

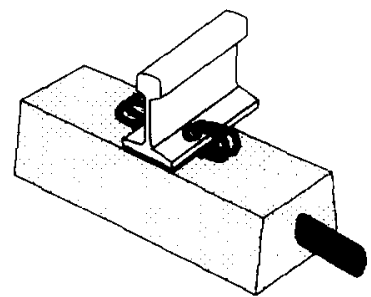

(e)

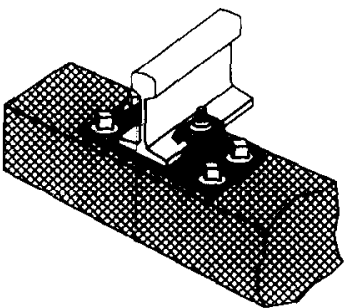

Fig. 2. Rail fastener systems intended for plain track. (a) Nabla fasteners on bibloc concrete sleeper, (b) Vossloh fasteners on monobloc concrete sleeper, (c) 'R heda modifiziert' two-stage soft fastener with Vossloh fasteners used in ballastless track, with sleepers cast into concrete slab, (d) DE spring clips on bibloc concrete sleeper, (e) wooden sleeper with K-fasteners. 
TABLE 1

Static Incremental Vertical Stiffnesses of Rail Fasteners in $\mathrm{MN} \mathrm{m}^{-1}$ for Various Preloads (Clips Omitted)

\begin{tabular}{lrrrr}
\hline Fastener & \multicolumn{4}{c}{ Preload $(k N)$} \\
\cline { 2 - 5 } & 20 & \multicolumn{1}{c}{40} & 60 & \multicolumn{1}{c}{80} \\
\hline 1. 4.5 mm ribbed pad/Nabla fastener & 170 & 170 & 300 & 760 \\
2. Zw687a/Vossloh fastener & 600 & 970 & 1300 & 1700 \\
3. Rheda modifiziert & 26 & 26 & 26 & 26 \\
4. FC9 pad/DE spring clips & 130 & 250 & 380 & 530 \\
5(b). EVA/wooden sleeper/K-fastener & 81 & 130 & 130 & 130 \\
\hline
\end{tabular}

In each case, the sleeper was omitted from the test rig, and the fasteners attached directly to the lower block, for which special mounting holes were made where necessary. For the wooden sleeper, the measurement was also carried out with part of the sleeper (length $0.5 \mathrm{~m}$ ) mounted in the test rig, as the stiffness of the sleeper was found to be lower than that of the fastener.

Table 1 lists incremental static stiffnesses for the vertical direction measured as a function of load. All of these systems are found to be progressive except for the Rheda system and the wooden sleeper. System 1 reveals a particularly large increase in stiffness for high preloads, which can be associated with the geometry of the pad-the gaps formed by the ribs in the pad become filled, leading to stiffening.

The vertical and lateral high-frequency stiffnesses measured for the various systems are listed in Table 2. The corresponding frequency ranges are also shown. In these frequency ranges the stiffness was found to be approximately constant, and the stiffness value was found by fitting a straight line to the

TABLE 2

High-Frequency Dynamic Stiffnesses of Rail Fasteners Measured Under Preload with Clips Attached. External Load $40 \mathrm{kN}$, with Preload Due to Clips in Addition

\begin{tabular}{lcccccc}
\hline Fastener & \multicolumn{3}{c}{ Vertical } & \multicolumn{2}{c}{ Lateral } \\
\cline { 2 - 7 } & $\begin{array}{c}\text { Dynamic } \\
\text { stiffness } \\
M N m^{-1}\end{array}$ & $\begin{array}{c}\text { Frequency } \\
\text { range } \\
H z\end{array}$ & $\begin{array}{c}\text { Damping } \\
\text { loss factor } \\
(-)\end{array}$ & $\begin{array}{c}\text { Dynamic } \\
\text { stiffness } \\
M N m^{-1}\end{array}$ & $\begin{array}{c}\text { Frequency } \\
\text { range }\end{array}$ \\
\hline 1. $4.5 \mathrm{~mm}$ ribbed pad/Nabla & $2250^{6^{*}}$ & $300-1000$ & 0.08 & 380 & $300-1000$ \\
2. Zw687a/Vossloh fastener & 3550 & $600-1000$ & 0.1 & 280 & $230-1000$ \\
3. Rheda modifiziert & 60 & $100-550$ & 0.25 & 50 & $200-550$ \\
4. FC9 pad/DE spring clips & 3000 & $370-900$ & 0.13 & 22 & $220-470$ \\
5(a). EVA pad/DE spring clips & 4000 & $600-1000$ & 0.13 & 265 & $230-1000$ \\
5(b). EVA/wooden sleeper/K & 265 & $200-800$ & 0.05 & 71 & $230-500$ \\
\hline
\end{tabular}

${ }^{*}$ Result very sensitive to tension in fasteners. 
measured transfer function. The values listed are all subject to a tolerance of $5-10 \%$, corresponding roughly to $0.5-1 \mathrm{~dB}$ in the measured accelerations. The high stiffness of some of these systems for the vertical direction meant that the lower limit of the frequency range was rather higher than desired, whilst for the lateral direction the upper limit was restricted. The loss factors are less reliable, variations of $\pm 50 \%$ being common. The values shown are the average over the frequency range measured.

Table 3 shows the effect of the preload on the dynamic stiffnesses of two of the systems. The damping loss factor is found to be virtually independent of preload. The effect of the clips is also shown explicitly in Table 3. Both systems here had the same type of DE spring clip. In the vertical direction these clips had very low stiffness, but a stiffening effect was observed in the pad since the clips increase the preload (by approximately $20 \mathrm{kN}$ ). This was also the case for the other type of clip tested. To apply the preload, the clips experience a deflection of the order of $\mathrm{mm}$, so that the small amplitudes of pad deflection considered here will not affect this preload significantly. In the lateral direction, however, the extra stiffness could not be completely explained by the additional preload, and it appeared that the clip could be represented by an additional stiffness of approximately $60 \mathrm{MN} \mathrm{m}^{-1}$ in parallel with the pad. The other clips were not tested in this respect.

In order to compare the static stiffnesses of Table 1 and the dynamic stiffnesses given in Table 2 it is necessary to allow for the extra preload of the clips (approx. $20 \mathrm{kN}$ ) which was not present in the static stiffness measurements. It is therefore realistic to compare the static stiffnesses for $60 \mathrm{kN}$ preload with the dynamic stiffnesses for $40 \mathrm{kN}$. This reveals dynamic:static

TABLE 3

High-Frequency Dynamic Stiffnesses of Rail Fasteners Measured Under Various Preloads without and with DE Spring Clips Attached

\begin{tabular}{|c|c|c|c|c|c|}
\hline \multirow[t]{2}{*}{ Fastener } & \multirow[b]{2}{*}{ Direction } & \multirow[b]{2}{*}{$\begin{array}{c}\text { External } \\
\text { preload } \\
k N\end{array}$} & \multicolumn{2}{|c|}{ Without clips } & \multirow{2}{*}{$\begin{array}{l}\text { With clips } \\
\text { Dynamic } \\
\text { stiffness } \\
M N m^{-1}\end{array}$} \\
\hline & & & $\begin{array}{l}\text { Dynamic } \\
\text { stiffness } \\
M N m^{-1}\end{array}$ & $\begin{array}{c}\text { Damping } \\
\text { loss factor } \\
(-)\end{array}$ & \\
\hline $\begin{array}{l}\text { 4. FC9 cork-rubber pads } \\
(4.5 \mathrm{~mm})\end{array}$ & Vertical & $\begin{array}{l}20 \\
40 \\
80\end{array}$ & $\begin{array}{l}1060 \\
1530 \\
2750\end{array}$ & $\begin{array}{l}0.19 \\
0.19 \\
0.18\end{array}$ & $\begin{array}{c}- \\
- \\
-\end{array}$ \\
\hline \multirow[t]{2}{*}{$\begin{array}{l}\text { 5(a). EVA pads } \\
(4.5 \mathrm{~mm})\end{array}$} & Vertical & $\begin{array}{l}20 \\
40 \\
80\end{array}$ & $\begin{array}{l}2120 \\
3000 \\
3850\end{array}$ & $\begin{array}{l}0.14 \\
0.13 \\
0.11\end{array}$ & $\begin{array}{l}3000 \\
4000 \\
5960\end{array}$ \\
\hline & Lateral & $\begin{array}{l}20 \\
40 \\
80\end{array}$ & $\begin{array}{l}141 \\
178 \\
200\end{array}$ & $\begin{array}{l}0.18 \\
0.18 \\
0.18\end{array}$ & $\begin{array}{l}237 \\
266 \\
282\end{array}$ \\
\hline
\end{tabular}


ratios of between 2 and 8 . This highlights the danger of using static values or even very low frequency dynamic values, which are more typically 1.2-2 times the static stiffness, for predicting high-frequency track behaviour.

\section{Fasteners for application on bridges}

In addition to the systems described above, four systems used for direct fastening of rails to bridges in The Netherlands have been measured (Fig. 3):

(6) NS adjustable fastener 'regelbare bevestiging' comprising $4.5 \mathrm{~mm}$ FC9 cork-rubber pad, a steel plate (tapered but with an average thickness of approx. $20 \mathrm{~mm})$ and a second resilient layer of cork-rubber $(10 \mathrm{~mm}$ thick FC6 material and $2 \mathrm{~mm}$ FC897). The upper layer is fastened by DE spring clips, and lower layer by coil-sprung bolts.

(7) Variant of the adjustable fastener with the FC6 pad replaced by $12 \mathrm{~mm}$ FC104.

(8) Corkelast embedded rail. The rail is embedded in elastomeric material within a steel channel. The material under the rail foot consists of $8 \mathrm{~mm}$ of Corkelast and a $12 \mathrm{~mm}$ continuous pad of cork-rubber (FC14).

(9) Variant of Corkelast embedded rail, with FCl4 material replaced by $12 \mathrm{~mm}$ of a softer cork-rubber material (FC28).

These systems were all tested with $0.3 \mathrm{~m}$ of rail in place between the upper block and the fastener system, the rail head being held in a groove in the upper block by the preload. The response at the upper side of the fastener was mcasurcd on the rail to climinate any effect of relative movement between the block and the rail. The last two systems, which are continuous rail fasteners, comprised a $0.3 \mathrm{~m}$ length of rail embedded in an equally long special channel. The first two, on the other hand, are normally used at $0.6 \mathrm{~m}$ intervals, so a valid comparison requires that all the stiffnesses are converted to stiffness per unit length of rail (in $\mathrm{N} \mathrm{m}^{-2}$ ). Furthermore, the preload applying to the embedded rail sections was set at $20 \mathrm{kN}$, rather than $40 \mathrm{kN}$, to allow for the distributed nature of the support.

(a)

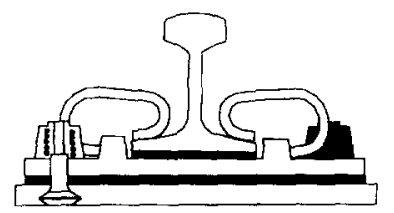

(b)

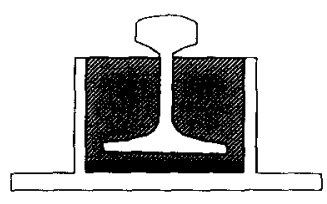

Fig. 3. Rail fastener systems intended for application on bridges. (a) NS adjustable fastener, (b) embedded rail. 
TABLE 4

High-Frequency Dynamic Stiffnesses of Rail Fasteners for Bridges Measured Under Preload

\begin{tabular}{|c|c|c|c|c|c|c|}
\hline \multirow[t]{2}{*}{ Fastener } & \multirow[b]{2}{*}{$\begin{array}{c}\text { External } \\
\text { preload } \\
k N\end{array}$} & \multicolumn{3}{|c|}{ Vertical } & \multicolumn{2}{|c|}{ Lateral } \\
\hline & & $\begin{array}{l}\text { Dynamic } \\
\text { stiffness } \\
M N m^{-1}\end{array}$ & $\begin{array}{c}\text { Stiffness } \\
\text { per metre } \\
M N m^{-2}\end{array}$ & $\begin{array}{c}\text { Damping } \\
\text { loss factor } \\
(-)\end{array}$ & $\begin{array}{c}\text { Dynamic } \\
\text { stiffness } \\
M N m^{-I}\end{array}$ & $\begin{array}{c}\text { Stiffness } \\
\text { per metre } \\
M N m^{-2}\end{array}$ \\
\hline $\begin{array}{l}\text { 6. NS adjustable } \\
\text { fastener (FC6) }\end{array}$ & $40^{(*)}$ & 200 & 330 & 0.15 & 30 & 50 \\
\hline $\begin{array}{l}\text { 7. Variant with } \\
\text { FCl04 }\end{array}$ & $40^{(*)}$ & 75 & 125 & 0.10 & 14 & 23 \\
\hline $\begin{array}{l}\text { 8. Embedded rail } \\
\text { (with FC14) }\end{array}$ & 20 & 60 & 200 & 0.15 & 14 & 47 \\
\hline $\begin{array}{l}\text { 9. Embedded rail } \\
\text { (with FC28) }\end{array}$ & 20 & 35 & 120 & 0.17 & 4.5 & 15 \\
\hline
\end{tabular}

Notes: *excluding preload due to clips. Tolerance $c .5 \%$ for stiffness, $10-20 \%$ for damping.

The results are given in Table 4. When converted to stiffness per unit length of rail, the results show that, compared to the adjustable fastener (system 6), the embedded rail (system 8 ) has about $60 \%$ of the stiffness, and the two softer variants ( 7 and 9 ) have 38 and $36 \%$ of the stiffness, respectively. These systems are all significantly softer than the railpads designed for ballasted track (Table 2), although the Rheda fastener (system 3), at $100 \mathrm{MN} \mathrm{m}^{-2}$, has a slightly lower stiffness than any of those included in Table 4.

Although valid measurements could be made for the range $100-1000 \mathrm{~Hz}$, not all of the stiffness valucs are valid for the whole frequency range, due to the occurrence of internal resonances. Figure 4 shows the measured frequency-dependence, which in some cases can lead to an increase in stiffness by up to a factor of 10 . The values in Table 4 are the average values in the lower frequency flat part of the curves of Fig. 4.

\section{FIELD MEASUREMENTS}

An alternative method for determining the stiffness and damping of rail fasteners, which can also be used to obtain the complex stiffness of the ballast, is to use measurements of the frequency response of a track in situ. By comparing the results with predictions using a theoretical model, the relevant parameter values can be estimated. Such a method has been used by several researchers. $^{8}$

A suitable model for ballasted track for the frequency range under consideration (up to $1 \mathrm{kHz}$ ) for the vertical direction is a Timoshenko beam on a 


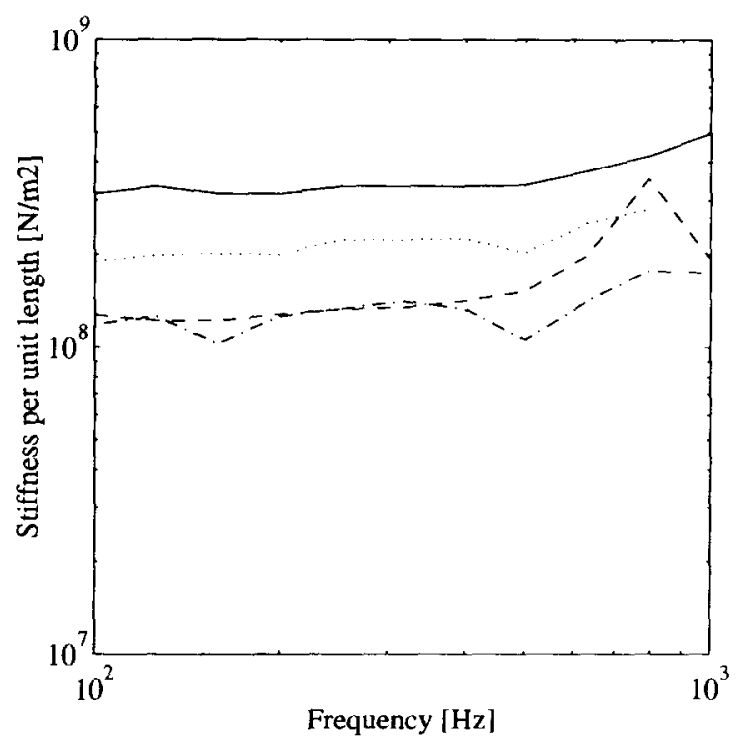

(a)

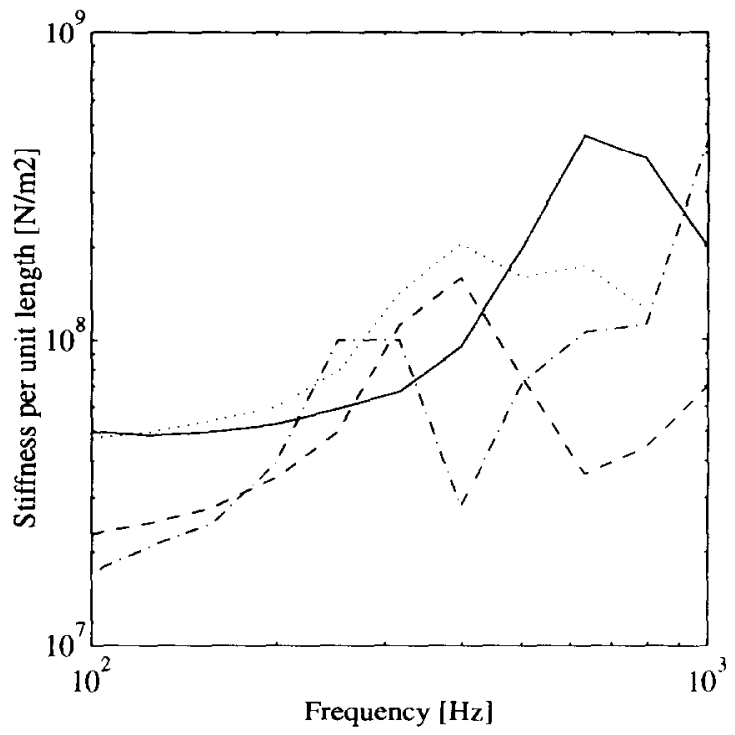

(b)

Fig. 4. Dynamic stiffness per unit length as a function of frequency, (a) vertical direction, (b) lateral direction. _ _ adjustable fastener with FC6; - - adjustable fastener with FC104; $\cdots$ embedded rail with FC14; $\cdots$ embedded rail with FC28.

spring-mass-spring foundation. ${ }^{9,10}$ The mass represents the sleeper, and the two resilient layers are formed by the rail pads and ballast, respectively. For some of the systems, in particular the embedded rail, a single layer model is 
sufficient. For relatively stiff rail pads, the vertical resonance of the rail on the rail pad can occur close to the 'pinned-pinned' frequency at $1 \mathrm{kHz}$, the latter being where half a bending wavelength in the rail equals the sleeper spacing (normally $0.6 \mathrm{~m}$ for the systems considered here). In this case a periodically supported beam model is required. ${ }^{9}$ For softer rail pads, an equivalent continuously supported rail model is sufficient. In both models a hysteretic damping has been used for both the pads and ballast.

When deriving the pad stiffness from such comparisons of measured and predicted frequency responses, the accuracy is rather limited, certainly no better than that applying to the test rig measurements. To obtain the pad stiffness to within $\pm 10 \%$, the eigenfrequency of the track associated with the rail pad must be identified within $\pm 5 \%$, since the stiffness is related to the square of this eigenfrequency. Also the effective mass of the sleeper at the relevant frequency must be known. For bibloc sleepers resonant effects do not usually occur in the frequency range up to $1 \mathrm{kHz}$, but for monobloc concrete or wooden sleepers, representation of the sleeper by a mass limits the reliability of the estimate of pad stiffness. On a concrete slab or a bridge the impedance under the fastener is sufficiently high not to contribute to the eigenfrequency of the rail on the rail pad.

Curve fitting for the lateral direction is more difficult than for the vertical direction, as torsion in the rail also plays a role in its lateral dynamic behaviour. A track model taking this into account is therefore required. ${ }^{3,11}$ No results are given here for the lateral direction.

Field measurements are available of the unloaded frequency response of most of the systems which have been measured in the test rig. Measurements used hammer excitation of the rail, the response mcasurement using an accelerometer. ${ }^{10}$ Figures 5 and 6 show two examples of measured frequency response functions, for systems 4 and 8 , along with a fitted curve based on the implied parameters for pad (and ballast) stiffness and damping. The results for all of the available systems are listed in Table 5 and compared with the results from the test rig. The latter are generally considerably higher, due to the fact that a preload is applied in the test rig and not in the field measurements.

For system 4 an 'unloaded' measurement in the test rig is also available (Table 3), the load of $20 \mathrm{kN}$ corresponding to the preload of the clips only. This compares favourably with the value estimated by curve fitting. For three other systems, the unloaded value has been estimated using the loading factor derived from the static stiffnesses in Table 1 . The ratio between the static stiffnesses at 20 and $60 \mathrm{kN}$ is applied as a correction to the loaded dynamic stiffness to give an estimate of the unloaded dynamic stiffnes. These ratios are between 1 and 3. Applying the same procedure to the results of system 4 as a check gives $1030 \mathrm{MN} \mathrm{m}^{-1}$, which is within $3 \%$ of the measured unloaded stiffness. Very reasonable agreement is found between the stiffness 


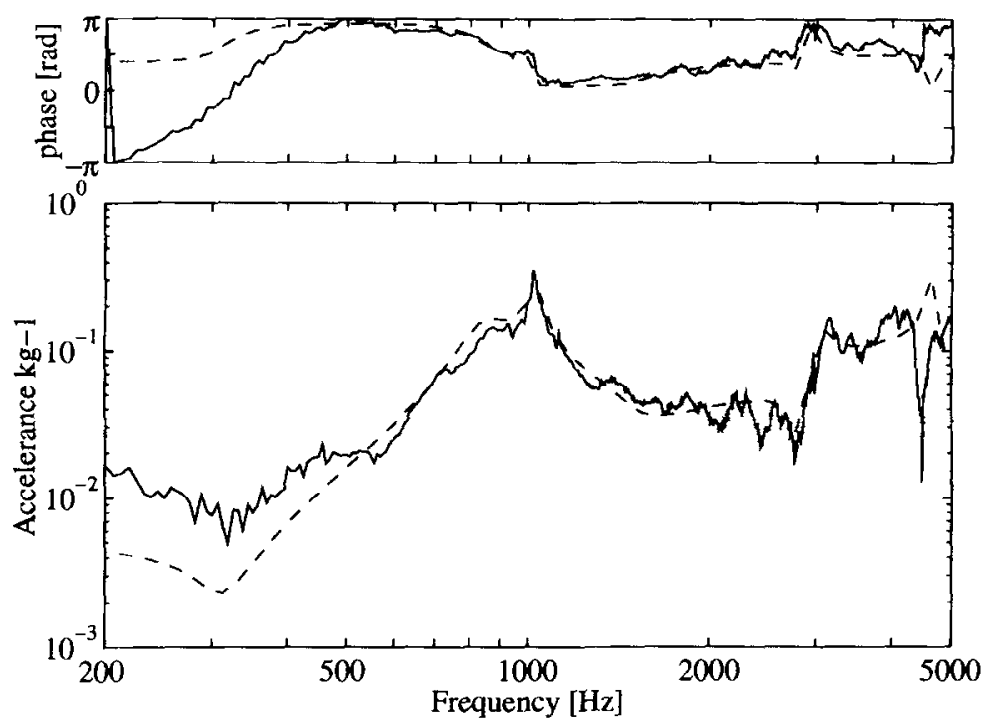

Fig. 5. Vertical frequency response function (acceleration/force) of track 4 (FC9 cork-rubber pads on bibloc concrete sleepers). _ _ measured; - - - predicted using TWINS periodically supported rail model, UIC 54 rail, pad stiffness $9 \times 10^{8} \mathrm{~N} \mathrm{~m}^{-1}$, pad loss factor 0.25 , half-sleeper mass $122 \mathrm{~kg}$, sleeper spacing $0.6 \mathrm{~m}$, ballast stiffness (real part per sleeper end) $6 \times 10^{7} \mathrm{~N} \mathrm{~m}^{-1}$, loss factor 1.0 .

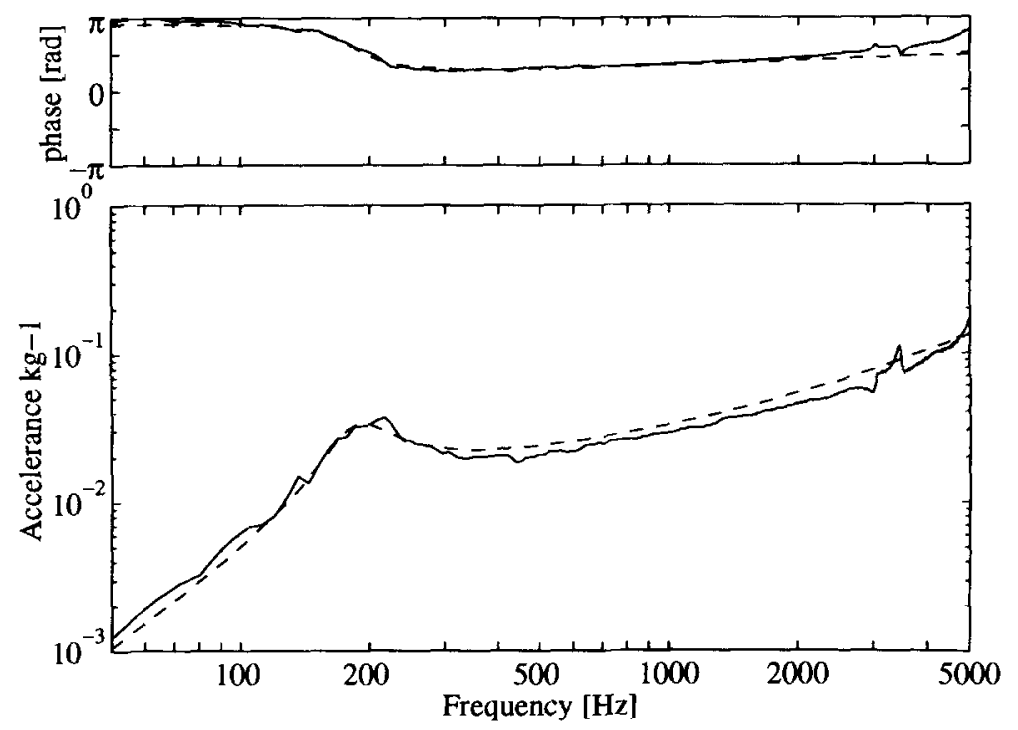

Fig. 6. Vertical frequency response function (acceleration/force) of track 8 (embedded rail with $\mathrm{FCl4}$, on a bridge). - - measured; - - predicted using TWINS continuously supported rail model, UIC 54 rail, pad stiffness $7.5 \times 10^{\prime} \mathrm{N} \mathrm{m}^{-2}$, pad loss factor 0.25 , on rigid foundation. 
TABLE 5

High-Frequency Dynamic Stiffnesses of Rail Fasteners Measured in Test Rig and Derived from Field Measurements (for Systems 8 and 9 Values are per metre of Rail)

\begin{tabular}{lcccc}
\hline Fastener & Type of sleeper, etc. & $\begin{array}{c}\text { Test rig } \\
M N m^{-1} \\
\text { loaded }\end{array}$ & $\begin{array}{c}\text { Test rig } \\
M N m^{-I}\end{array}$ & $\begin{array}{c}\text { Field tests } \\
M N m^{-l} \\
\text { unloaded } \\
\text { unloaded }\end{array}$ \\
\hline 2. Zw687a/Vossloh fastener & Concrete monobloc & 3550 & $1600^{*}$ & 1000 \\
3. Rheda modifiziert & Concrete slab & 60 & $60^{*}$ & 60 \\
4. FC9 pad/DE spring clips & Concrete bibloc & 3000 & 1060 & 900 \\
5. EVA/K-fastener & Wooden & 4000 & 2120 & 500 \\
6. NS adjustable fastener(FC6) & Steel bridge & $265^{+}$ & $165^{*+}$ & \\
8. Embedded rail (FCl4) & Steel bridge & $200 \mathrm{MN} \mathrm{m}^{-2}$ & - & $75 \mathrm{MN} \mathrm{m}^{-2}$ \\
9. Embedded rail (FC28) & Steel bridge & $120 \mathrm{MN} \mathrm{m}^{-2}$ & - & $45 \mathrm{MN} \mathrm{m}^{-2}$
\end{tabular}

*Estimated from loaded value using ratio of static stiffnesses at 20 and $60 \mathrm{kN}$ from Table 1.

${ }^{\ddagger}$ Transfer stiffness of sleeper.

derived from field measurements and the estimate of unloaded stiffness from the test rig. For the monobloc concrete sleeper, the result from the field tests is probably distorted by the neglect of sleeper resonances in the track modcl. For the wooden sleeper, the local deformation of the sleeper dominates compared with the stiffness of the (rather stiff) rail pad, and a 'pad' stiffness of about 3 times the transfer stiffness of the sleeper appears appropriate from the field measurement.

Damping loss factors of the rail fasteners have also been derived from field tests from both the bandwidth of the resonance (Figs 5 and 6) and the decay of vibration along the track. The values so derived are mostly around 0.25 . This is generally about a factor 2 higher than the damping which was measured directly in the test rig. The reason for this difference is not known, but may be related to variations between pad stiffnesses, sleeper spacings, etc. from one sleeper to the next. Such variations would tend to introduce variations in resonance frequency and would increase the attenuation of vibration along the track.

Results for the ballast stiffness are, of course, not generally dependent on the fastener system and so have not been listed separately. Vertical stiffness magnitudes obtained by curve fitting to measured frequency responses have been found in the range $50-150 \mathrm{MN} \mathrm{m}^{-1}$ per sleeper end. These values apply in the frequency range up to about $300-400 \mathrm{~Hz}$ where the ballast stiffness most affects the frequency response; no measurements have been taken below $50 \mathrm{~Hz}$. At one site where the largest of these values was found, repeat measurements at the same site 10 months later yielded stiffnesses a factor of 
3 smaller. The phase of this complex stiffness is found to be in the range 25$65^{\circ}$, indicating significant radiation damping due to energy transmission into the ground. Lateral ballast stiffness amplitudes are also found to lie in the range $50-100 \mathrm{MN} \mathrm{m}^{-1}$ per sleeper end.

\section{AMPLITUDES OCCURRING IN TRACK}

As noted in the introduction, the stiffness of resilient elements can be amplitude-dependent. It is therefore important to know the amplitudes of the deflections occurring in rail pads in the track. Two distinct effects need to be separated: the large amplitude quasi-static deflections within the pads due to the moving loads of a train passing over the track, and the small amplitude deflections occurring at high frequencies. For the latter, only the response to roughness excitation is considered here, the effects of gross deformities such as wheel flats being ignored.

Predictions of the high-frequency strains in the rail pad have been performed using the TWINS model ${ }^{1}$ and are shown in Fig. 7 for two of the tracks considered here. These are based on the loaded stiffnesses as listed in Table 2. Results are shown for two roughness spectra, representing smooth wheels and rails and a corrugated wheel or rail surface with a corrugation

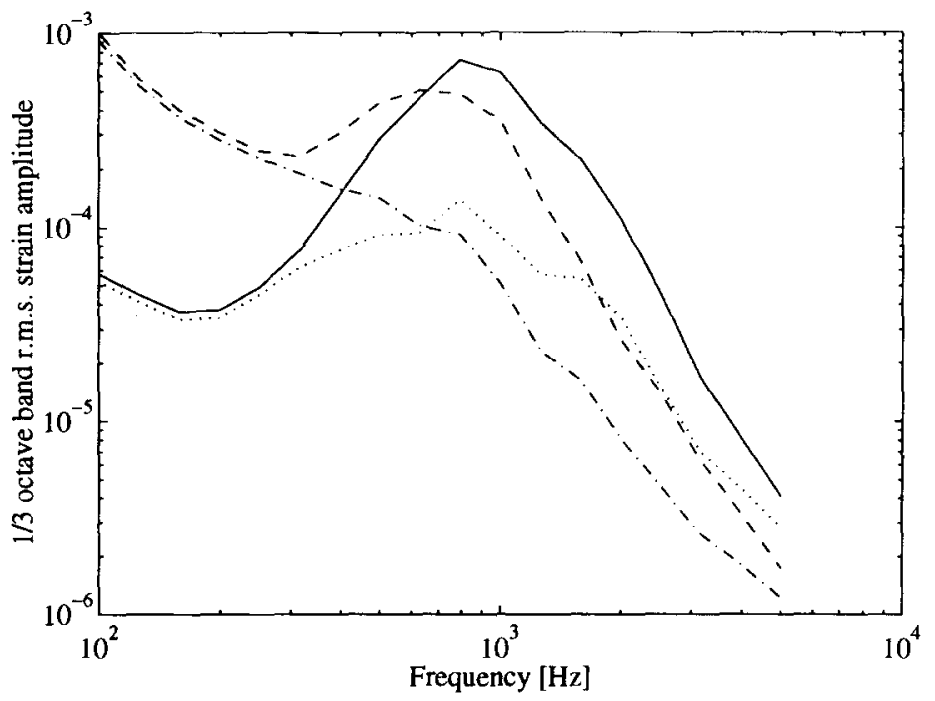

Fig. 7. R.m.s. strain amplitudes in rail pads predicted using TWINS continuous track model. For corrugated surface, wavelength $50 \mathrm{~mm}$, peak-trough amplitude $30 \mu \mathrm{m}$ : —— FC9 pads (system 4); - - Rheda (system 3). For typical smooth wheel-rail surfaces: .... FC9 pads (system 4); -... Rheda (system 3). 
wavelength of around $50 \mathrm{~mm}$ and a peak-to-trough amplitude of $30 \mu \mathrm{m}$. The predictions are based on a continuous track model, and a train speed of $140 \mathrm{~km} \mathrm{~h}^{-1}$ has been used. From these results it is found that the high frequency component of strain is less than $0.03 \%$ (r.m.s.) for the low roughness case, for normal values of the pad stiffness. These amplitudes are sufficiently small to allow the small amplitude measurements from the test rig to be used to determine pad stiffness. For the highly resilient Rheda system, the strain is only significant at low frequencies. For the frequency range shown the r.m.s. amplitude is $0.12 \%$. For the corrugated case, the r.m.s. strain amplitudes increase to $0.12 \%$ for the stiff pad, and $0.16 \%$ for the soft pad. These values appear within the limits of what is acceptable to allow low amplitude measurements to be used to characterise the stiffness (comparing with results for butyl rubber) ${ }^{4}$ For still higher amplitudes of corrugation, the strain amplitude may become important in influencing the pad stiffness.

To calculate the quasi-static strain, a nonlinear calculation model is required. However, to give a simple estimate of the order of magnitude of this quasi-static strain, consider a load of $40 \mathrm{kN}$ in combination with the (incremental) static stiffness for a $40 \mathrm{kN}$ preload (Table 1). This gives peakpeak strain amplitudes between $0.8 \%$ (for system 2 ) and $5 \%$ (for system 1 ). System 3 produces a $15 \%$ strain (for a $10 \mathrm{~mm}$ pad thickness), as does system 7. The embedded rail systems have lower strains as the thickness of elastomeric material under the rail foot is $20 \mathrm{~mm}$. These strain amplitudes are all large compared with the limits of $0.1-0.4 \%$ discussed above for low amplitude behaviour. Nevertheless, the quasi-static effects have been allowed for in terms of a static preload. More research is needed to establish whether the transient nature of this loading modifies the behaviour more than just a static loading effect. It would seem unlikely for the systems with low strains but may play a significant role in the softer systems.

\section{FUTURE DEVELOPMENTS}

The laboratory measurement method described here can readily be applied to higher frequencies. A single measurement arrangement is limited to a frequency range of about one decade, so in order to measure beyond $1 \mathrm{kHz}$, a second set of masses would be required. The upper limit was partly determined by resonances of the blocks at around $1500 \mathrm{~Hz}$. To measure up to $4 \mathrm{kHz}$, these resonances must be increased in frequency by a factor of about 4 , so that the blocks should be reduced in dimensions by 4 , or by a factor 64 in mass. Such dimensions (a diameter of typically $0.2 \mathrm{~m}$ ) would mean that most systems could still be mounted in the rig, although the embedded rail sections would need to be shortened. 
It is also desirable to take account of the temperature-dependence of the high-frequency stiffness and the damping, about which little information is currently available.

With hindsight it is clear that both loaded and unloaded stiffnesses should always be measured for the frequency range under consideration. The test rig described in this paper was originally developed for testing resilient elements such as engine mountings which are subject to a steady preload. A rail fastener experiences a rather large, varying quasi-static load during the passage of a train. Where the strains introduced in the resilient elements are large (i.e. for relatively soft fasteners) this can lead to transient effects in the dynamic properties of the elastomeric material, as discussed above. In this case a test method in which the quasi-static loading can be simulated would be more appropriate. Nevertheless for most of the systems tested, the strains in the elastomer itself are limited to less than 5\% and the effects of transient loading are likely to be none other than those measured under various static preloads.

\section{CONCLUSIONS}

A laboratory test method has been described for measuring the high frequency dynamic stiffness of resilient rail fasteners in the region $100-1000 \mathrm{~Hz}$. The stiffness is found to be virtually independent of frequency in the range studied apart from the occurrence of internal resonances in two-layer systems. Dynamic-to-static stiffness ratios of between 2 and 8 have been found. The stiffness is also strongly depcndent on the preload in many cases, increasing by factors up to 3 under a $40 \mathrm{kN}$ load.

Comparisons with stiffness values derived from field measurements of track frequency responses show good agreement once the effect of preload has been allowed for. The damping loss factors apparent in the field measurements, from the width of resonance peaks and the decay of vibration along the track, are generally higher than those measured in the test rig. However, this may be related to variations between pad stiffnesses, sleeper spacings, etc. introducing variations in resonance frequency and additional spatial attenuation in the rail vibration.

\section{ACKNOWLEDGEMENTS}

Part of the work described here has been carried out under the direction and funding of the European Rail Research Institute (ERRI), committee C163, in collaboration with Vibratec, France. The initial application of the method 
to rail fasteners and the measurements on systems for use on bridges have been carried out in collaboration with NS with funding from the Dutch Ministry of Environment, which is also gratefully acknowledged. The measurements were performed by J. J. D. M. Akkermans and F. G. P. van der Knaap.

\section{REFERENCES}

1. Thompson, D. J., Hemsworth, B. and Vincent, N., Experimental validation of the TWINS prediction program for rolling noise, part 1: description of the model and method. Journal of Sound and Vibration, 1996, 193, 123-135.

2. Thompson, D. J., Fodiman, P. and Mahé, H., Experimental validation of the TWINS prediction program for rolling noise, part 2: results. Journal of Sound and Vibration, 1996, 193, 137-147.

3. Thompson, D. J., Wheel-rail noise: theoretical modelling of the generation of vibrations. Ph.D. thesis, University of Southampton, 1990.

4. Freakley P. K. and Payne, A. R., Theory and Practice of Engineering with Rubber. Applied Science Publishers Ltd, London, 1978, pp. 74-82.

5. Hinsch, P., Einige Untersuchungen zum Messen dynamischer Moduln von Elastomeren. Kautsch. Gummi, Kunstst., 1989, 42, 752-756.

6. Verheij, J. W., Multi-path sound transfer from resiliently mounted shipboard machinery. Doctoral thesis, TNO Institute of Applied Physics, Delft, 1982.

7. Verheij, J. W., Measuring sound transfer through resilient mountings for separate excitation with orthogonal translations and rotations. Proceedings of Inter Noise 80, Miami, FL, 1980, pp. 723-726.

8. Knothe, K. and Grassie, S. L., Modelling of railway track and vehicle/track interaction at high frequencies. Vehicle System Dynamics, 1993, 22, 209-262.

9. Thompson, D. J. and Vincent, N., Track dynamic behaviour at high frequencies. Part 1: theoretical models and laboratory measurements. Vehicle System Dynamics Supplement, 1995, 24, 86-99.

10. Vincent, N. and Thompson, D. J., Track dynamic behaviour at high frequencies. Part 2: experimental results and comparisons with theory. Vehicle System Dynamics Supplement, 1995, 24, 100-114.

11. Thompson, D. J., Wheel-rail noise generation, part III: rail vibration. Journal of Sound and Vibration, 1993, 161, 421-446. 